\title{
INBREEDING IN AN ISLAND POPULATION OF THE GREAT TIT
}

\author{
A. J. VAN NOORDWIJK ${ }^{1,2}$ AND W. SCHARLOO ${ }^{1}$ \\ ${ }^{1}$ Department of Population and Evolutionary Biology, University of Utrecht, \\ Padualaan 8, 3508 TB Utrecht and Institute for Ecological Research, \\ Kemperbergerweg 67, 6816 RM Arnhem, The Netherlands
}

Received July 1, 1980. Revised October 21, 1980

The deleterious effects of inbreeding may have been recognized since the start of civilization, possibly based on experience in breeding livestock and the occurrence of congenital defects in the offspring of relatives in man. The basis of these deleterious effects could only be understood after the rediscovery of Mendel's laws. The discovery of recessive lethal genes in mice and the realization that inbreeding promotes homozygosity followed soon. Because the relative difference between the proportion of homozygotes produced by inbred and by outbred pairs is larger when the frequency of the gene involved is smaller, the noxious effects of inbreeding can be explained by the increase in the level of homozygosity of rare recessive deleterious genes. The data available for man, domesticated animals and plants show that harmful effects of inbreeding are present in all crossbreeding organisms (Lerner, 1954; Cavalli Sforza and Bodmer, 1971; Wright, 1977) and suggest that deleterious recessive genes are numerous. The general occurrence of deleterious recessives was confirmed by studies in Drosophila species. With the help of chromosomes marked with dominant genes and carrying inversions to suppress crossing-over, chromosomes from wild populations were made homozygous. Up to $40 \%$ were found to carry recessive lethal genes (Dobzhansky, 1955). The technique which allows such a direct demonstration is presently only available in Drosophila.

Only in humans has inbreeding been studied in any depth in situations with a natural partner choice. However, in man relatives seem to be taken as partners more naturally by some people than by others (Bittles, 1977). Little evidence exists on inbreeding depression in animal populations under natural conditions. Although cases of inbreeding have been reported from population studies in birds, where nestlings were ringed and parents identified on the nest, the numbers involved were too small to allow more than a qualitative statement on the effect of inbreeding (Richdale, 1957; Bulmer, 1973; Greenwood et al., 1978). Yet inbreeding avoidance, presumably selected for by inbreeding depression, is used to explain a wide variety of phenomena (see for instance Bateson, 1978; Bengtsson, 1978). There is clearly a need for quantitive data on inbreeding in natural populations (May, 1979). The data from the long-term population studies of the Great Tit (Parus major) carried out at the Institute for Ecological Research at Arnhem (The Netherlands) allow us to give quantitative estimates of the occurrence and the effects of inbreeding. We will compare the occurrence and the detectability in a mainland and in an island population. Reduced hatching success will be shown to exist both for inbred zygotes and in clutches of inbred females.

\section{Population Study of the Great Tit}

The Great Tit is a common hole-breeding passerine that readily accepts nestboxes and can therefore be studied with relative ease. In the study areas nestboxes are provided and these are inspected weekly during the breeding season. Date of first egg-laying, clutch size, date of hatching, hatching rate and nesting success are observed or deduced from observations, using age estimates of the nestlings and the knowledge that one egg is laid every day. Eggs that are still present when there are nestlings at least two days old (in first clutches, four days in later 
clutches) are scored as eggs that failed to hatch. Nestlings are ringed when six to twelve days old with a standard numbered ring. At the same time the parents are trapped in the nestbox by means of a spring-operated door. If one of the parents is not caught, a second attempt is usually made within a few days. In addition, most adult birds are color-ringed which allows identification of females during incubation. The data used in this study come from two areas: 1) Vlieland, an island in the Waddensea (see Fig. 1). The tits are breeding in all wooded areas, consisting of coniferous and mixed coniferous and broadleaved trees. The whole island population is under observation. 2) Hoge Veluwe, a partly coniferous and partly mixed wood on poor soil on the mainland. The study area is situated in a large wooded area and emigration from, and immigration into the study area occur frequently.

A detailed description of the methods used in collecting the data and the study areas is given by Van Balen (1973) and Kluyver (1971). For several years experiments have been carried out in both areas. The study of the relatively isolated population on Vlieland was started to investigate the density dependent component of survival in the Great Tit. During 19601963 and 1967-1968 the reproduction of every pair was reduced to about $30 \%$ of normal, mostly through the removal of eggs. The results were that survival of both adults and offspring increased, population size was not notably affected and there was no increase in immigration (Kluyver, 1971). With respect to inbreeding and effective population size $\left(N_{e}\right)$ this probably had little effect since the reduction in the variance in the number of offspring per pair was counteracted by the higher survival rate of adults. From 1970 till 1974 many pairs producing late broods were removed from the population.

\section{Methods}

We will adhere to the following terminology: a clutch is laid by a female and her male partner, the pair. If they are related their offspring will be inbred. In

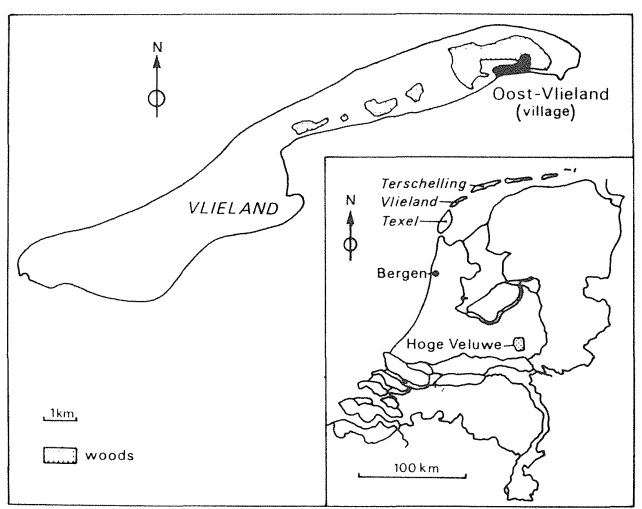

FIG. 1. The island of Vlieland and the position of localities mentioned in the text.

evaluating the genealogies we start with the pair, the laying female and its partner. The degree of inbreeding and the relatedness of pairs is expressed in Wright's coefficient of inbreeding, $F$, the average proportion of the genome that is homozygous through descent.

Pedigrees were made for all breeding individuals up to and including their greatgrandparents, although even on Vlieland few pedigrees are complete. For all clutches where the parents were identified, the pedigrees of female and male were checked for common ancestors. Thus the lowest degree of inbreeding that could be detected is having one greatgrandparent in common $(F=1 / 128)$, while the highest degree of inbreeding not detected in complete pedigrees is the mating of a "greatgreatgrandparent" with a "greatgreatgrandchild" ( $F=1 / 32)$. Great Tits start breeding when one year old, and from then onwards have an annual survival rate of roughly $50 \%$, thus up to $5 \%$ of the breeding adults is five years or older and may have greatgreatgrandchildren as potential partners. In fact, we found one pair where the male is a grandfather and independently a greatgreatgrandfather of the female.

In evaluating the effect of inbreeding, we have used three different parameters: 1) Eggs I, eggs failing to hatch sensu stricto. These are defined as those eggs that were still present in the nest after they 
TABLE 1. Data on the parentage and the occurrence of inbreeding from the Hoge Veluwe (1955-1978) and Vlieland (1958-1978), based on clutches of all types. Autochthonous is ringed as a nestling in the study area.

\begin{tabular}{lcc}
\hline & Hoge Veluwe & Vlieland \\
\hline Total number of clutches & 3,642 & 1,706 \\
Female and male identified (A) & $2,601(71 \%)$ & $1,297(76 \%)$ \\
Female unknown & $79(2 \%)$ & $23(1 \%)$ \\
Male unknown & $620(17 \%)$ & $275(16 \%)$ \\
Female and male unknown & $342(9 \%)$ & $111(7 \%)$ \\
Female and male autochthonous $(\mathrm{B})$ & $460(18 \%$ of A) & $839(65 \%$ of A) \\
Only female autochthonous & $371(14 \%$ of A) & $117(9 \%$ of A) \\
Only male autochthonous & $781(30 \%$ of A) & $235(18 \%$ of A) \\
Neither autochthonous & $989(38 \%$ of A) & $106(8 \%$ of A) \\
All grandparents of both female & $20(4 \%$ of B) & $280(33 \%$ of B) \\
and male known (C) & 1 & $132(47 \%$ of C) \\
Detected inbreeding in C & $23(5 \%$ of B) & $241(29 \%$ of B) \\
Detected inbreeding in B & $27(1 \%$ of A) & $245(19 \%$ of A) \\
Detected inbreeding in A & & \\
Average degree of inbreeding & 0.0011 & 0.015 \\
Based on A & 0.0063 & 0.036 \\
Based on B & - & \\
Based on C & & \\
\hline
\end{tabular}

should have hatched at the latest. 2) Eggs II, eggs that failed to hatch sensu lato. These are defined as the difference between clutch size and the observed number of hatched young (both alive and dead). Small nestlings that die are often removed by the parents, and these will be included in this category. Most authors assume that eggs failing to hatch will not be removed by the parents, unless they were accidentally broken (Perrins, 1979). However, it seems likely that this broad definition is less sensitive to error of observation than the narrow definition. 3) Brood reduction, defined as the difference between the number of eggs and the number of fledglings, expressed as a proportion of clutch size.

\section{Occurrence of Inbreeding}

Estimates of the average degree of inbreeding depend to a large extent on the assumptions made about the origin of immigrants, i.e., individuals that were not ringed as nestlings in the study area and whose parents are not known. By formulating two extreme assumptions it is possible to give a lower and an upper limit for the average degree of inbreeding. If all immigrants come from a great distance and are therefore not related to each other or to autochthonous individuals (i.e., ringed as nestling in the study area), they will not be involved in inbreeding. This implies that there is no undetected inbreeding and that the observed inbreeding should be related to the total number of pairs (estimate A, Table 1). If, on the other hand, immigrants are only distinguished from autochthonous individuals because they cross an artificial boundary of the study area, this may cause undetected inbreeding. Although it is less likely that they are involved in parent-offspring or in full-sib pairs if one parent is autochthonous, we should relate the detected inbreeding only to pairs with fully known pedigrees, for which it is certain that no undetected inbreeding occurred (estimate C, Table 1). For the Vlieland populations there is some incidental evidence for both assumptions. Two breeding adults were ringed as nestlings elsewhere, one in Bergen some $70 \mathrm{~km}$ away and one on the neighboring island of Terschelling (Fig. 1). Up to ten broods have fledged without having been ringed during the whole study period, mainly from nestboxes in private gardens that were detected only after the breeding season. The percentages 
TABLE 2. The occurrence of inbreeding in individual years on Vlieland, based on pairs. The means are unweighted means of the anmual averages.

\begin{tabular}{|c|c|c|c|c|c|c|c|c|}
\hline \multirow[b]{3}{*}{ Years } & \multirow{3}{*}{$\begin{array}{l}\text { Total } \\
\text { number } \\
\text { of pairs }\end{array}$} & \multirow{3}{*}{$\begin{array}{l}\text { Number } \\
\text { of pairs } \\
\text { with known } \\
\text { grandparents }\end{array}$} & \multirow{2}{*}{\multicolumn{2}{|c|}{$\begin{array}{l}\text { Inbreeding in } \\
\text { pairs with fully } \\
\text { known grandparents }\end{array}$}} & \multirow{2}{*}{\multicolumn{2}{|c|}{$\begin{array}{l}\text { Other cases } \\
\text { of inbreeding }\end{array}$}} & \multicolumn{2}{|c|}{ Average degree of inbreeding } \\
\hline & & & & & & & \multirow{2}{*}{$\begin{array}{c}\text { Pairs } \\
\text { with known } \\
\text { grandparents }\end{array}$} & \multirow[b]{2}{*}{ All pairs } \\
\hline & & & $F \geqslant 1 / 16$ & $F<1 / 16$ & $F \geqslant 1 / 16$ & $F<1 / 16$ & & \\
\hline $1958-64$ & 172 & 9 & 1 & 3 & 7 & 2 & .0347 & .0097 \\
\hline 1965 & 67 & 15 & 5 & 3 & 5 & 2 & .0615 & .0221 \\
\hline 1966 & 58 & 14 & 4 & 3 & 3 & 4 & .0458 & .0186 \\
\hline 1967 & 49 & 13 & 4 & 6 & - & 7 & .0361 & .0124 \\
\hline 1968 & 50 & 15 & 3 & 6 & 3 & 2 & .0396 & .0168 \\
\hline 1969 & 39 & 8 & 2 & 2 & - & 4 & .0553 & .0120 \\
\hline 1970 & 38 & 10 & 3 & 2 & 1 & 1 & .0469 & .0142 \\
\hline 1971 & 49 & 9 & 3 & 1 & 2 & - & .0455 & .0118 \\
\hline 1972 & 58 & 11 & 6 & 1 & 1 & 1 & .1020 & .0233 \\
\hline 1973 & 59 & 14 & 4 & 3 & 1 & 2 & .0542 & .0141 \\
\hline 1974 & 58 & 12 & 3 & 3 & 4 & 3 & .0209 & .0138 \\
\hline 1975 & 54 & 14 & 4 & 5 & - & 2 & .0335 & .0091 \\
\hline 1976 & 59 & 15 & 2 & 4 & - & 3 & .0271 & .0117 \\
\hline 1977 & 94 & 28 & 4 & 11 & 5 & 3 & .0311 & .0181 \\
\hline 1978 & 68 & 22 & 2 & 3 & 2 & 1 & .0178 & .0109 \\
\hline \multirow[t]{2}{*}{ Total } & 783 & 209 & 50 & 56 & 33 & 38 & & \\
\hline & & & & & & & $\begin{aligned} \bar{x} & =.0441 \\
\mathrm{SD} & =.0211 \\
\mathrm{SE} & =.0056\end{aligned}$ & $\begin{aligned} \bar{x} & =.0149 \\
\mathrm{SD} & =.0042 \\
\mathrm{SE} & =.0011\end{aligned}$ \\
\hline
\end{tabular}

of identified parents are very similar in the Hoge Veluwe and the Vlieland populations (Table 1), but the immigration rates are very different. The effect of immigration on our knowledge of pedigrees is evident from the relative proportion of clutches where all grandparents of both the male and the female are known. Thus, the large difference in detected inbreeding between both populations could be partly spurious.

On Vlieland the geometric mean of the annual numbers of breeding individuals is about 100 . Thus, the minimum estimate of the average amount of inbreeding $(0.015$, Table 1$)$ is about three times the amount expected in a closed random mating population of the same size $\left(N_{e} \approx 100\right.$, $\left.1 /\left(2 N_{e}\right)=0.005\right)$. There are several potential causes. Although fluctuations in population size have been taken into account in the calculation of $N_{e}$ they may have had an unforeseen influence on the age structure, especially in combination with the effect of the experiments that were carried out. However, as is shown in Table 2, the average amount of inbreeding is fairly constant from year to year considering the small numbers involved. The high value in 1972 is solely the result of having four brother-sister pairs in a single year.

There are many cases of inbreeding of a more complicated nature. An example is shown in Figure 2. It is difficult to formulate a precise frame of reference, but we suspect that there are more complicated cases than expected. There are several indications that some individuals are much more likely to get involved in inbreeding than others. In data on individuals born in 1965 or later we find the following: given that a female is inbred, she is also related to the male in 24 out of 51 cases, whereas if she is not known to be inbred this is only 102 out of 511 . If we consider the females that have had two different partners, 11 were related to both, 17 to one and 48 to none of them. Only 5 are expected to be related to both partners, from the observed frequency of inbreeding in this group, or 3.8 from the general incidence of inbreeding.

According to population genetic theory two deviations from ideal populations might be responsible for a high level of inbreeding, i.e., the subdivision of the population and the variance in number of 


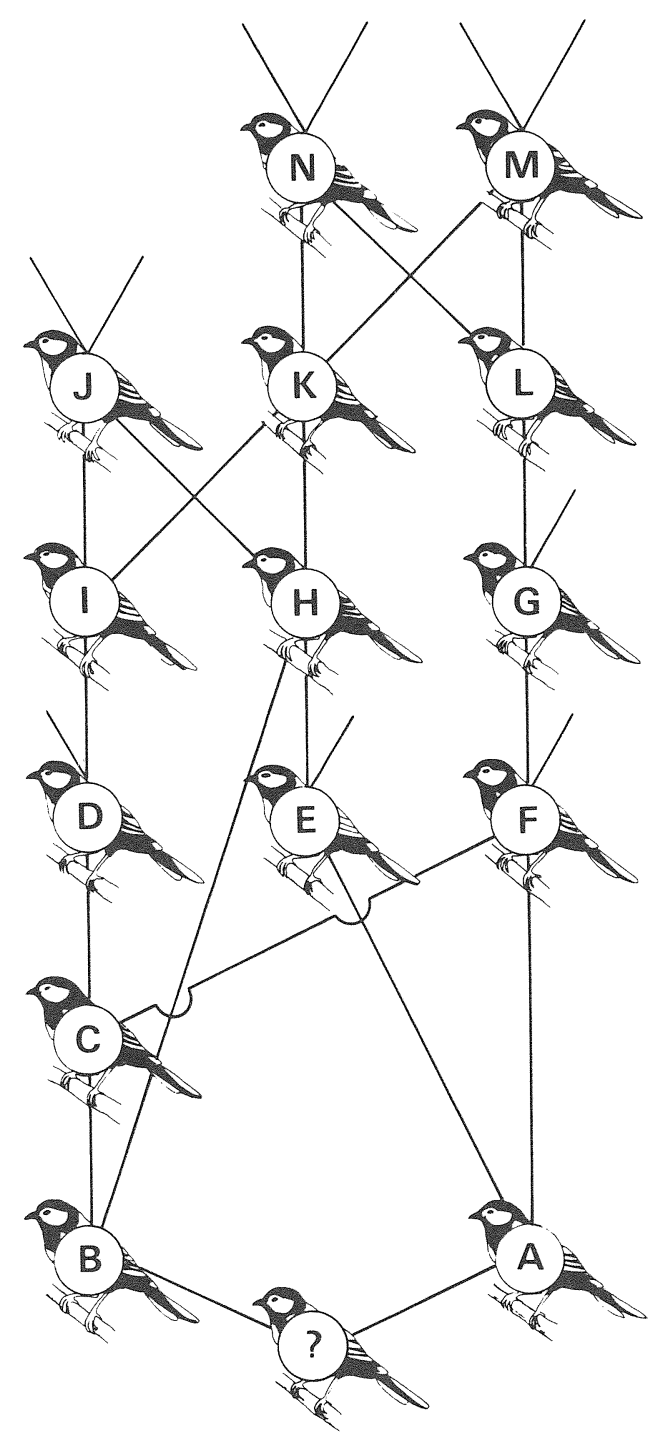

FIG. 2. A complicated pedigree of Great Tits from Vlieland. All individuals shown are at least as related as greatgrandparents to $\mathrm{A}$ or $\mathrm{B}$. (There are ten relations between $\mathrm{A}$ and $\mathrm{B}, F=0.145)(\mathrm{BCFA}$, BHEA, BCDIKHEA, BCDIJHEA, BKMLGFA, BHKNLGFA, BCDIKNLGFA, BCDIKMLGFA, BCFGLM KHEA, BCFGLNKHEA).

offspring (see, e.g., Crow and Kimura, 1970). The suitable habitat is not continuous on Vlieland. There are four small areas that are about $1 \mathrm{~km}$ apart, a much larger wooded area and the village which borders on the large area (see Fig. 1). At first sight this subdivision might mean that the effective size of the subpopulations should be used as a reference rather than the over-all population size. Although a further analysis of the relation between dispersal and inbreeding is needed, preliminary results show that the average degree of inbreeding in the smaller areas is lower than average, while both inbred females and inbred males are also under-represented in the smaller areas. This is an unexpected result and so far the only explanation that we can offer is that in the most western and smaller area, the number of immigrants seems disproportionately high. There are a few individuals that occur in many pedigrees of related pairs. By counting the number of grandchildren observed as breeding adults we found a female who had 37 grandchildren as breeding adults. This would mean that for about five years $10-20 \%$ of the breeding population consisted of its grandchildren. These counts (Table 3) should be treated with some reservation, because they have not been corrected for birds still alive or with progeny still alive. Further, the removal of birds from the population will also undoubtedly have had a large effect. There is, however, a large variance in the number of offspring which become breeding adults. This will enhance inbreeding. Some speculative explanations for this large variation will be offered below.

\section{Inbreeding Might Go Undetected}

The estimates of the occurrence and the effect of inbreeding will be affected when the probability of identifying a pair is smaller as a result of inbreeding. Most of the parents are identified only when they have nestlings of at least one week old. If inbreeding depression were to result in a failure of the clutch before this moment, the observed cases of inbreeding would give an underestimate of the occurrence of inbreeding. The effect on our estimates of inbreeding depression would probably be much more serious. It is only possible to obtain an impression in an indirect way after making several additional assumptions. Data on clutches that failed, i.e., 
produced no fledglings, are given in Table 4. In very few cases both parents were identified, but in many cases only one parent, usually the female, was identified. In a majority of these a repeat clutch is known where the other parent was identified. If we assume that no change of partner has taken place, they can be classified as related or not related. The number of related pairs and the number of inbred females is higher than expected from their over-all frequencies, but only the latter significantly so (Fisher exact, $P<.05)$. This suggests that inbreeding depression can be a cause of failure. If failure raises the frequency of a change of partners, the observed frequency of related pairs will be an underestimate.

If there is an interaction between the observability and the effects of inbreeding, it is possible that there is a still higher proportion of inbreeding in the pairs where the partner is also unknown in a repeat clutch.

\section{Effect of Inbreeding}

The number of cases of inbreeding observed in the Hoge Veluwe is too small to draw any quantitative conclusion on inbreeding depression. The general impression is that about half the clutches are normal, (Appendix 1), while in the other half, especially the number of eggs that failed to hatch, is very high. However, no relationship with the degree of inbreeding is apparent, probably due to the small numbers involved.

In a preliminary analysis of the data from Vlieland it soon became clear that effects of the laying female being inbred and effects of the egg being inbred are both present. These will be dealt with separately, and clutches where the female was both inbred and related to her partner are not analyzed but given in Appendix 2. As the proportion of parents identified as producing clutches that failed is low and may be erratic, the analyses are restricted to clutches from which at least one nestling has fledged.

All clutches have been grouped according to their $F$-values, with class values of

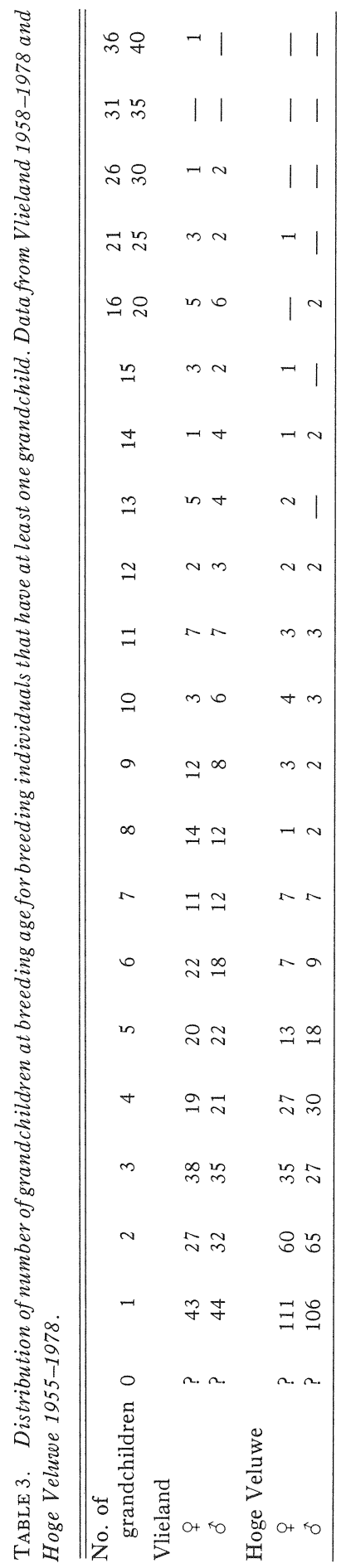


TABLE 4. Data on the parentage of clutches that failed. Data from Vlieland 1965-1978.

\begin{tabular}{|c|c|c|c|c|c|}
\hline & $\begin{array}{l}q \text { and } \delta \\
\text { identified }\end{array}$ & $\begin{array}{l}\text { One parent } \\
\text { identified, } \\
\text { partner from } \\
\text { other clutch } \\
\text { in same year }\end{array}$ & $\begin{array}{c}q \text { and } \delta \\
\text { unidentified }\end{array}$ & Total & Expected \\
\hline \multicolumn{6}{|l|}{ First clutches } \\
\hline not inbred and unrelated & 4 & 9 & - & 13 & \\
\hline Related & 3 & 8 & - & 11 & 5.6 \\
\hline o inbred & 0 & 5 & - & 5 & 2.1 \\
\hline \multirow[t]{2}{*}{ Partner unknown } & - & 6 & 30 & 36 & \\
\hline & 7 & 28 & 30 & 65 & \\
\hline \multicolumn{6}{|l|}{ Other clutches } \\
\hline not inbred and unrelated & 3 & 12 & - & 15 & \\
\hline Related & 0 & 6 & - & 6 & 6.5 \\
\hline ㅇ inbred & 0 & 6 & - & 6 & 2.4 \\
\hline \multirow[t]{2}{*}{ Partner unknown } & - & 4 & 9 & 13 & \\
\hline & $\overline{3}$ & $\overline{28}$ & $\overline{9}$ & $\overline{40}$ & \\
\hline
\end{tabular}

$(1 / 2)^{n}(n=2 \ldots 7)$. Relative date of laying and size of first clutches of related pairs and inbred females are not different from the population mean.

The distributions of the numbers of eggs failing to hatch in the clutches of related parents are given in Figures 3 and 4. Both the average number not hatching and the proportion of clutches in which any eggs fail to hatch increase with the degree of inbreeding. If first and later clutches are analyzed separately the same trends are found in both, although the numbers of later clutches are very small. The results are influenced by the fact that some pairs contributed only one clutch while others are known from up to five clutches. There are, however, other dependencies that will also be present in an analysis based on pairs rather than clutches. A number of individuals were paired with different relatives in subsequent years, mostly at different degrees of inbreeding. Whether inbreeding depression is found or not is not entirely independent in these cases. Moreover, there are also some cases, where, for example, two brothers are paired with cousins which are sisters. It will be shown below that inbred males are not likely to affect breeding success. They were included in Table 5 which gives the average number of eggs failing to hatch as a proportion of clutch size and the average brood reduction, for seven degrees of in- breeding, together with the regression on $F$ based on average values per pair. Data on inbred females with a related male were excluded. The result is rather similar to that shown in Figures 3 and 4.

All these regressions are based on cases with $F>0$. A control group was made of all clutches where all eight grandparents of the pair were known, but where no inbreeding was detected. The values for eggs failing to hatch and brood reduction in this group should be equal to the intercept values of the regression equations. The agreement is good (Table 5); the regression equations would change little if the data on the control group were included. The slope of the regression is the same for eggs failing to hatch sensu stricto and eggs failing to hatch sensu lato, but the intercept value is roughly three times as high in the latter. If one were to use brood reduction to measure inbreeding depression, a smaller effect of inbreeding is found (Table 5). The intercept value is twice the value found in eggs II, but the slope is less than that found for eggs failing to hatch. The square of the correlation coefficient gives a measure for the proportion of the variance explained by the regression. It is the highest for eggs II and lowest for brood reduction. If the failure to hatch has a genetic cause one expects similar proportions of failing eggs in different clutches of the same pair. The cor- 


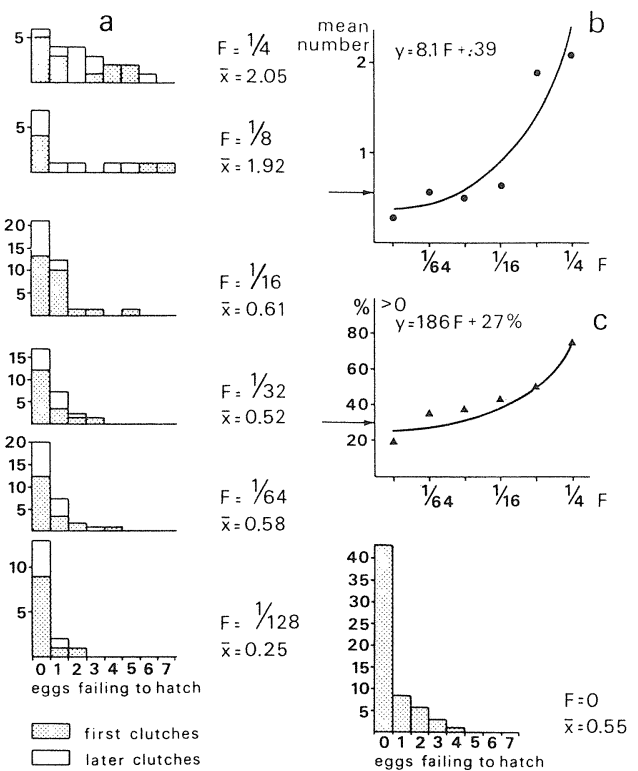

FIG. 3. a) Distribution of the numbers of eggs failing to hatch I. b) Regression of mean number of eggs failing on degree of inbreeding. c) Regression of percentage of clutches with one or more eggs failing to hatch on degree of inbreeding. Arrow indicates value found for $F=0$.

relations in proportion of eggs failing and in brood reduction between different clutches of the same pair $(r=0.48(n=$ 44) for eggs I, $r=0.62(n=44)$ for eggs II and $r=0.42(n=34)$ for brood reduction) indicate that especially for eggs II a high proportion of eggs failing in one clutch will be followed by a high proportion in other clutches of the same pair. Whereas these correlations are significant for related pairs, the same correlations are very close to zero within the control group.

This indicates that a common cause for the death of offspring in different clutches of the same pair, which must be expected if genetic factors are responsible, is only present in the inbred group. Most of the deaths which result from increased homozygosity seem to occur before or at hatching. The proportion of eggs failing to hatch as a result of inbreeding is highest in eggs I, but the chance of finding eggs that failed to hatch may not have been constant. The regression of brood reduc-
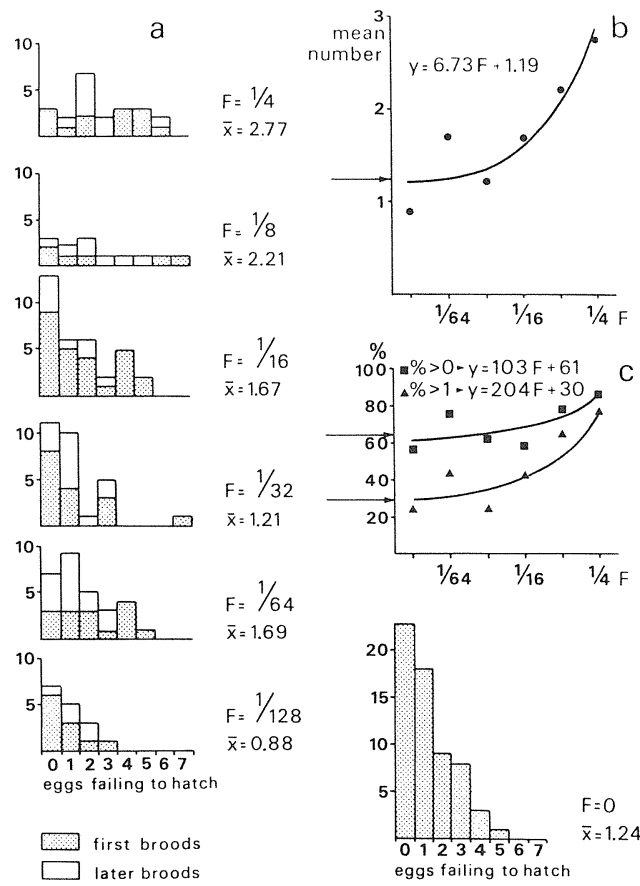

first broods

later broods

eggs failing

FIG. 4. a) Distribution of the numbers of eggs failing to hatch II. b) Regression of mean number of eggs failing on degree of inbreeding. c) Regression of percentage of clutches with one or more eggs failing to hatch on degree of inbreeding. Arrow indicates value found for $F=0$.

tion on degree of inbreeding has a smaller slope than was found for both measurements of eggs failing to hatch. This might be expected if some of the causes of death in later stages of the nest are negatively correlated with brood size. An early reduction in brood size may result in more available food per nestling for the remaining young, reducing their chance to die.

\section{Recruitment}

Selection should be studied over a complete life-cycle. Taking the life-cycle from breeding adult to breeding adult is the most convenient. Some of the nestlings were observed as breeding adults in later years. This provides a basis for evaluating selection for or against inbreeding.

The first question is whether the recruitment per fledgling was lower from broods of related parents, or in other words whether inbred individuals had a 


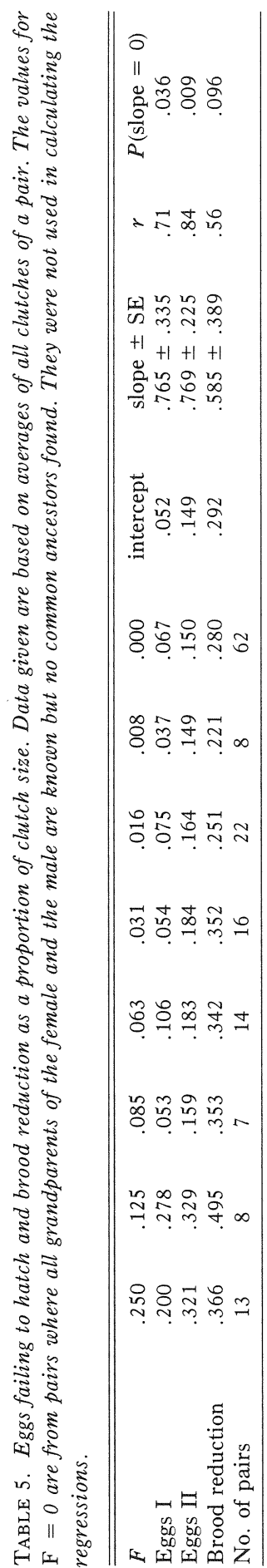

TABLE 6. Recruitment from first clutches of related pairs (number of individuals). Expectations are based on the average recruitment from clutches where no inbreeding is known, and with the same clutch size in the same year. In I on the recruitment/fledgling, and in II on the recruitmentlegg.

\begin{tabular}{lccc}
\hline \hline & $\begin{array}{c}F= \\
1 / 4 \text { and } 1 / 8\end{array}$ & $1 / 16$ and $1 / 32$ & $1 / 64$ and $1 / 128$ \\
\hline Expected I & 11.7 & 36.6 & 29.0 \\
Observed & 16 & 44 & 17 \\
Expected II & 14.5 & 36.3 & 24.7 \\
\hline
\end{tabular}

lower survival from fledging to the next breeding season. Recruitment rates are different between years. Therefore we used the recruitment rates from clutches where no inbreeding was detected and which had the same clutch size in the same year, for calculation of the expected number of recruits. To avoid the effect of small numbers we grouped our data in three categories of severity of inbreeding.

The results shown in Table 6 do not indicate any additional deaths after fledging due to inbreeding. On the contrary, even on a basis of the number of recruited adults per egg, pairs with severe and intermediate degrees of inbreeding do slightly better than unrelated pairs.

The first possibility is that higher recruitment is only a chance effect due to the small numbers.

A second hypothesis is that an early reduction in brood size would increase the amount of food per nestling that is available, resulting in a higher nestling weight. A higher weight at fledging enhances survival in Great Tits (Dhondt, 1971; Perrins and Moss, 1975; Perrins, 1979). The same mechanism might explain the reduction in deaths of nestlings in later stages in broods of related pairs.

A third hypothesis is based on the fact that selection causes a reduction in effective population size (Robertson, 1961). Since some individuals leave more offspring than others, these individuals have more related offspring in the population than other individuals. Likewise the chance that another individual in the population is related is highest for these off- 
spring, and thus their chance of becoming involved in inbreeding. Now, if the traits that made their ancestor successful are partly inherited, one may expect that in a finite population inbreeding pairs have a higher proportion of these favored traits, and so do their offspring. This will then probably be reflected in a higher rate of recruitment per fledgling. An effect similar to the third hypothesis can arise when some territories are better than others. Pairs breeding in high quality territories will produce more offspring, with a superior condition enabling them to occupy better than average territories.

These hypotheses are feasible and they can serve as illustrations of the type of problems that can be encountered in real populations, but that cannot be solved with separate concepts from either population dynamics or population genetics.

Decreased fertility. - Individuals that are inbred could have reduced fertility. At the same time, if a maternal or paternal effect on the hatching rate exists, this could be detected from these data. At an anecdotal level we know that a female that incubated an empty nest and another female that bred for at least 18 days without any eggs hatching (13-14 days is normal) were both heavily inbred.

The regressions on the degree of inbreeding, using only those cases where either the male or the female was inbred and where they were unrelated, are given in Table 7. The two highest (into $F \geqslant 1 / 8$ ) and the two lowest degrees of inbreeding (into $F \leqslant 1 / 64$ ) have been combined to ensure at least ten clutches per group. It seems that a maternal effect is present in the hatching rate, while the presence of a paternal effect is doubtful.

The recruitment from clutches where the female or the male was inbred is extremely high. On the basis of the number of fledglings we would expect a total of 28.3 recruits $(27.3$ on the basis of the number of eggs), while the number observed is 45 . There are six clutches (out of 28) in this group from which $50 \%$ or more of the fledglings were recruited. In the control group $(F=0)$ there is only one case out
TABLE 7. Regression of number of eggs failing to hatch and percentage of clutches with one or more such eggs on degree of inbreeding. A, In clutches where partners are related. $B$, In clutches where the female is inbred. $C$, In clutches sired by an inbred male. Cases where both partners were inbred or at least one parent was inbred and related to the partner were excluded. Data from Vlieland 1958-1978.

\begin{tabular}{lc}
\hline A Pairs & \multicolumn{1}{c}{$r$} \\
Number of eggs $\mathrm{I}=8.09 F+0.39$ & $0.85^{* *}$ \\
$\%$ cl. with $\mathrm{I}>0=186 F+27$ & $0.95^{* * *}$ \\
B $\%$ Inbred & \\
$\quad$ Number of eggs $\mathrm{I}=1.59 F+0.49$ & 0.45 \\
$\%$ cl. with $\mathrm{I}>0=155 F+31$ & $0.93^{*}$ \\
C Inbred & \\
Number of eggs $\mathrm{I}=.70 F+0.55$ & 0.86 \\
$\%$ cl. with $\mathrm{I}>0=-19 F+32$ & -0.52 \\
\hline$* P<.05$. & \\
$* * P<.01$. & \\
$* * *<<.005$. &
\end{tabular}

of 60 with more than $50 \%$ recruitment, a case where 2 out of 3 fledglings were recruited. Four cases where the father was inbred are 5 out of $8 ; 3$ out of $5 ; 4$ out of 6 ; and 2 out of 2 ; and two cases with the mother inbred are 5 out of 6 , and 4 out of 7. But even without these six cases the observed recruitment is above the expected. Thus the question what is special about inbred individuals seems to be worth further study. The absence of brood reduction in nests with an inbred father and a high recruitment must be expected when the high recruitment from clutches with related parents is caused by their better adaptation or because they have grown up in better territories. It would not be expected when the early brood reduction is responsible for a high recruitment per fledgling.

\section{Discussion}

There are several population studies of birds where inbreeding has been detected (e.g., Richdale, 1957; Bulmer, 1973; Harvey et al., 1978). The number of cases that were detected in these studies are few, and at best comparable to our data from the Hoge Veluwe. Although such data may allow some qualitative remarks about inbreeding depression, the data from Vlie- 
land are far better suited for such study. Yet even in the Vlieland data there are uncertainties and artifacts. Thus, the values given for the average amount of inbreeding and inbreeding depression must be regarded with caution.

However, it is more likely that these values are underestimates than that they are overestimates. Our data (Table 4) suggest that severe inbreeding depression could perhaps escape observation. But even the conclusion that the amount of inbreeding on Vlieland is higher than on the Hoge Veluwe is perhaps not fully justified, if one looks at the relative differences between the different methods to calculate the average amount of inbreeding in Table 1. It is not impossible that, had there been more pairs with fully known genealogies in the Hoge Veluwe, estimate C, where only pairs with fully known genealogies are considered, would have been comparable to that from Vlieland. Estimate B (only autochthonous pairs) is five times as large as estimate $A$ (all pairs) for the Hoge Veluwe, while on Vlieland this is 1.5 times. If the same relative proportions are applied for $\mathrm{B}$ and $\mathrm{C}$ the Hoge Veluwe estimate would be 0.04 . This shows to what extent the estimates depend on the underlying assumptions.

A decline in hatchability is one of the most prominent effects of inbreeding in poultry (Lerner, 1954), while a strong reduction in egg production is also found in many strains (Shoffner, 1948). Very similar results were obtained in a study of inbreeding depression in the Japanese Quail (Coturnix japonica) (Sittman et al., 1966). Hatchability was strongly affected both as a result of the zygote or of the mother being inbred. The authors also found a reduction in fertility of inbred adults, part of which was the result of total infertility in males. In our data on the Great Tit there are no indications of a smaller clutch size or a reduced fertility in inbred adults, with the exception of two unproductive females mentioned. However, their chances of being observed would be rather low. Such unobserved infertile inbreds would have no effect on the average num- ber of grandchildren at breeding age from a related pair, because the decrease in average production of pairs where one of the parents is inbred is cancelled by the equal increase in the production from related pairs.

Reduction in litter size is probably the most prominent effect observed in mammals (Wright, 1977). This is physiologically comparable to reduced hatching in birds. In humans still-birth and juvenile death are the most extensively studied (Cavalli-Sforza and Bodmer, 1971). There is an interesting analogy between the problems met in obtaining reliable data on spontaneous abortions as a result of inbreeding and the possible bias in our results because pairs are identified only during the later stages of the nesting period.

The presence of deleterious genes can be characterized as a number of lethal equivalents. One assumes that all reductions in viability are due to recessive lethals with complete expression, and estimates the frequency of lethal equivalents. The slope of the regression of eggs failing to hatch on degree of inbreeding (Table 5) indicates that a gamete contains on average 0.77 lethal equivalents, that is 1.5 per zygote. However, in contrast to comparable human data (Morton et al., 1956), our estimates are lower if more stages of the life-cycle are taken into account. This is a consequence of the different ecological situation in tits.

Continued inbreeding will exert a strong selection against lethals. It is possible that in a small population this results in absence or low frequency of lethal genes, a probable example is given by Ralls et al. (1979). It is unlikely that inbreeding would lead to a reduced frequency of lethal genes in the Vlieland Great Tits, given that about $10 \%$ of the breeding individuals are immigrants. (Table 1).

In considering the effect of inbreeding we have treated the complete failure separately. Incorporating these failures would still result in a marginally higher number of offspring from the heavily and intermediately related pairs compared to the rest of the population. However, if a 
clutch fails a repeat clutch is nearly always produced. This repeat clutch can even be followed by a second clutch. Furthermore Kluyver (1963) has suggested that brood reduction enhances the probability of a second brood.

It can be calculated that in the Vlieland population the failure of more than half of all eggs that fail to hatch can be attributed to the effect of inbreeding. An ecologist wanting to explain the failure of hatching would not succeed unless inbreeding was also studied.

The effects of inbreeding in early stages in the life-cycle are at least compensated in later stages. Although our observations show deleterious effects of inbreeding at hatching, they do not support the occurrence of selection against inbreeding, which is postulated in sociobiology (Wilson, 1976). In the Great Tit population on Vlieland, "fitter" individuals have a higher chance of becoming involved in inbreeding. Therefore the individuals that are inbreeding are on the average "fitter." This will have effects in two directions. On the one hand, this will counteract the decrease in production caused by inbreeding. On the other hand inbreeding depression will slow down the rate at which a favorable allele replaces its predecessor. However, for recessives the enhanced homozygosity will increase this rate. This is comparable to methods of rapid improvement of livestock by combined selection and inbreeding. The apparent compensation in later stages are a strong warning against the extrapolation from observations on a (small) part of the lifecycle.

Our results confirm the classical effects of inbreeding, juvenile mortality and reduced fertility, found in laboratory populations and livestock. However, these effects can be compensated by ecological processes affecting mortality, such as density dependent effects in the nestling phase. Our results show interaction between the genetics of inbreeding and the ecology of the population. Neglect of ecological aspects in population genetics were earlier responsible for rather unproductive efforts in relation to the concept of genetic loads (see Wallace, 1970).

Further analysis of the population structure, which should include the dispersal patterns, the average relatedness of neighbors, and the differences between individuals leaving many and those leaving no offspring, are to be undertaken. Considerable genetic variation exists for clutch size, date of laying, body size and egg dimensions in the populations and selection for the first two traits can be demonstrated (Van Noordwijk et al., in press). These data together with the earlier work on the ecology of the Great Tit (Kluyver, 1971; van Balen, 1973) suggest a dynamic picture of interactions between processes concerning the ecology and the genetics of populations. Their integration is necessary for understanding the mechanisms which ultimately determine survival and future evolution.

\section{SUMMARY}

During the long-term population study of the Great Tit, all nestlings were ringed and most parents were identified. This allows the construction of family-trees. In an island population of about 50 pairs we found a common ancestor in 19\% of the clutches where both parents were identified and in $47 \%$ of the clutches where the geneaologies were completely known up to the grandparents of the pair. The hatching of eggs is reduced by $7.5 \%$ for every $10 \%$ increase of $F$. The effect of inbreeding is smaller at the moment of fledging. The recruitment to the next generation at breeding age is not lower from related pairs than from other pairs with the same clutch size in the same year. There is a separate effect on the hatching rate if the female is inbred. However the recruitment from clutches where either the male or the female is inbred is twice as high as expected. This can be explained because a few individuals have produced many offspring. The offspring have a high chance of mating with a relative, but the adverse effects of inbreeding are offset by higher recruitment. There is no evidence that inbreeding is avoided. Neither is it 
clear that inbreeding avoidance would be selectively advantageous.

\section{ACKNOWLEDGMENTS}

The great care taken by Dr. H. N. Kluyver and later by Dr. J. H. van Balen to ensure that data collected by a large number of people can be treated as a single body has made this study possible. Special thanks are due to $H$. M. van Eck who collected most of the data on Vlieland from 1965 onwards and made a large contribution to their coding. The help of J. Visser in maintaining the Great Tit data base is gratefully acknowledged. We thank Dr. J. H. van Balen, Dr. G. de Jong and Dr. J. W. Woldendorp for stimulating discussions and their comments on the manuscript. We thank Messrs. D. Smit and C. Strijland for preparing the drawings and Miss E. Kool for typing the manuscript. The investigations were supported by the Foundation for Fundamental Biological Research (BION), which is subsidized by the Netherlands Organization for the Advancement of Pure Research (Z.W.O.).

\section{Literature Cited}

BALEN, J. H. VAN. 1973. A comparative study of the breeding ecology of the Great Tit Parus major in different habitats. Ardea 61:1-93.

Bateson, P. 1978. Sexual imprinting and optimal outbreeding. Nature 273:659-660.

Bengtsson, B. O. 1978. Avoiding inbreeding; at what cost? J. Theoret. Biol. 73:439-444.

Bittles, A. H. 1979. Incest reassessed. Nature 280:107.

Bulmer, M. G. 1973. Inbreeding in the Great Tit. Heredity 30:313-325.

Cavalli Sforza, L. L., AND W. F. Bodmer. 1971. The Genetics of Human Populations. W. H. Freeman, San Francisco.

Crow, J. F., AND M. Kimura. 1970. An Introduction to Population Genetic Theory. Harper and Row, N.Y.

Dhondt, A. A. 1971. The regulation of numbers in Belgian population of Great Tits, p. 532-547. In P. J. de Boer and G. R. Gradwell (eds.), Dynamics of Populations. Pudoc, Wageningen.

DoBSZHANSKY, TH. 1955. A review of some fundamental concepts and problems of population genetics. Cold Spring Harbour Symp. Quant. Biol. 20:1-15.

- 1946. The genetics of Natural Populations XIII. Recombination and variability in populations of Drosophila pseudo-obscura. Genetics 31:269-290.

Dubinin, N. P. 1946. On lethal mutations in natural populations. Genetics 31:19-38.

Greenwood, P. J., P. H. Harvey, ANd C. M. PerRINS. 1978. Inbreeding and dispersal in the Great Tit. Nature 271:52-54.

KLuYver, H. N. 1963. The determination of reproductive rates in Paridae. Proc. XIII Int. Ornithol. Congress 706-716.

- 1971. Regulation of numbers in populations of Great Tits (Parus major) p. 507-523. In P. J. den Boer and G. R. Gradwell (eds.), Dynamics of Populations. Pudoc, Wageningen.

Lerner, I. M. 1954. Genetic Homeostasis. J. Wiley and Sons, N.Y.

MAY, R. M. 1979. When to be incestuous. Nature 279:192-194.

Morton, N. E., J. F. Crow, And H. J. Muller. 1956. An estimate of the mutational damage in man from data on consanguineous marriages. Proc. Nat. Acad. Sci. USA 42:855-863.

Noordwijk, A. J. van, J. H. van Balen, AND W. SCHARLOO. Heritability of ecologically important traits in the Great Tit. Ardea In press.

Perrins, C. M. 1979. British Tits. Collins, London.

Perrins, C. M., AND D. Moss. 1975. Reproductive rates in the Great Tit. J. Anim. Ecol. 44:695706.

Ralls, K., K. Brugger, and J. BAlou. 1979. Inbreeding and juvenile mortality in small populations of ungulates. Science 206:1101-1103.

Richdale, L. E. 1957. A Population Study of Penguins. Clarendon Press, Oxford.

RoBERTSON, A. 1961. Inbreeding in artificial selection programmes. Genet. Res. 2:189-194.

SHOFFNER, R. N. 1948. The reaction of fowl to inbreeding. Poult. Sci. 27:448-452.

Sittmann, K., H. Abplanalp, and R. A. Fraser. 1966. Inbreeding depression in Japanese Quail. Genetics 54:371-379.

Wallace, B. 1970. Genetic Load. Prentice-Hall, Englewood Cliffs, N.J.

Wilson, E. O. 1976. The central problems of sociobiology, p. 205-217. In R. M. May (ed.), Theoretical Ecology. Blackwell Scientific Publications, Oxford.

Wright, S. 1977. Evolution and the genetics of populations, Vol. III. Experimental Results and Evolutionary Deductions. Univ. Chicago Press, Chicago.

Corresponding Editor: D. B. Wake 
APPENDIX 1. Cases of inbreeding found on the Hoge Veluwe 1955-1978. (Pair 4 and pair 11 have the same female; pair 11 and pair 12 have the same male.)

\begin{tabular}{|c|c|c|c|c|c|c|c|c|}
\hline & $\begin{array}{c}F \\
\text { Relatedness } \\
\text { of parents }\end{array}$ & Year & $\begin{array}{l}\text { Type of } \\
\text { clutch }\end{array}$ & $\begin{array}{l}\text { Clutch } \\
\text { size }\end{array}$ & $\underset{\mathrm{I}}{\text { Eggs }}$ & $\begin{array}{c}\text { Eggs } \\
\text { II }\end{array}$ & $\begin{array}{l}\text { Number } \\
\text { fledged }\end{array}$ & Remarks \\
\hline 1 & .25 & 1974 & 1 & 10 & 4 & 4 & 2 & 4 eggs removed \\
\hline \multirow[t]{2}{*}{2} & .25 & 1977 & 1 & 9 & 4 & 4 & 5 & \\
\hline & & 1977 & 2 & 5 & 0 & 1 & 0 & \\
\hline 3 & .25 & 1971 & rep. & 10 & 3 & 5 & 5 & \\
\hline \multirow[t]{2}{*}{4} & .25 & 1974 & 1 & 9 & 0 & 0 & 7 & \\
\hline & & 1976 & 1 & 9 & 0 & 1 & 8 & \\
\hline 5 & .125 & 1968 & 1 & 9 & 0 & 3 & - & all nestlings removed \\
\hline 6 & .125 & 1968 & 1 & 12 & 2 & 5 & - & all nestlings removed \\
\hline \multirow[t]{2}{*}{7} & .125 & 1971 & rep. & 7 & 5 & 5 & 2 & \\
\hline & & 1972 & 1 & 9 & 3 & 3 & 0 & \\
\hline 8 & .125 & 1971 & 1 & 11 & 1 & - & - & $\begin{array}{l}5 \text { eggs and later all } \\
\text { nestlings removed }\end{array}$ \\
\hline \multirow[t]{2}{*}{9} & .125 & 1975 & 1 & 8 & 0 & 0 & 6 & \\
\hline & & 1975 & 2 & 7 & 0 & 0 & 5 & \\
\hline 10 & .125 & 1974 & 1 & 12 & 1 & 2 & 7 & \\
\hline 11 & .063 & 1975 & 1 & 9 & 0 & 1 & 6 & \\
\hline \multirow[t]{2}{*}{12} & .063 & 1976 & 2 & 8 & 0 & 1 & 5 & \\
\hline & & 1977 & 1 & 7 & 1 & 2 & 5 & \\
\hline 13 & .031 & 1970 & 1 & 7 & 1 & 1 & 6 & \\
\hline 14 & .031 & 1972 & 1 & 6 & 4 & 4 & 0 & \\
\hline 15 & .031 & 1973 & 1 & 10 & 1 & 1 & 0 & \\
\hline 16 & .031 & 1970 & rep. & 8 & 0 & 2 & 2 & \\
\hline 17 & .016 & 1967 & rep. & 10 & 0 & 0 & 10 & \\
\hline \multirow[t]{2}{*}{18} & .016 & 1968 & 1 & 9 & 0 & 0 & - & all nestlings removed \\
\hline & & & rep. & 7 & 0 & 0 & 6 & \\
\hline \multirow[t]{2}{*}{19} & .016 & 1975 & 1 & 7 & 1 & 1 & 6 & \\
\hline & & 1976 & 1 & 7 & 0 & 0 & 7 & \\
\hline 20 & .008 & 1978 & 1 & 10 & 0 & 0 & 10 & \\
\hline
\end{tabular}


APPENDIX 2. Cases of inbreeding where the female is inbred and related to the male. A repeat clutch is a clutch following a first clutch that failed, a second clutch is the clutch laid after a first clutch which produced at least one fledgling. Superscript on clutch size give number of eggs removed in an experiment. Data from Vlieland.

\begin{tabular}{|c|c|c|c|c|c|c|c|c|c|}
\hline & $\begin{array}{c}F \\
\text { Relatedness } \\
\text { of pair }\end{array}$ & $\begin{array}{c}F \\
\text { female }\end{array}$ & $\underset{\text { male }}{F}$ & Year & $\begin{array}{l}\text { Type of } \\
\text { clutch }\end{array}$ & $\begin{array}{c}\text { Clutch } \\
\text { size }\end{array}$ & $\begin{array}{c}\text { Number } \\
\text { of eggs } \\
\text { failing I }\end{array}$ & $\begin{array}{c}\text { Number } \\
\text { of eggs } \\
\text { failing II }\end{array}$ & $\begin{array}{l}\text { Number } \\
\text { fledged }\end{array}$ \\
\hline 1 & .281 & .063 & .063 & 1966 & 1 & 9 & 3 & 4 & 4 \\
\hline 2 & .281 & .063 & .063 & 1972 & 1 & 9 & 5 & 6 & 3 \\
\hline \multirow[t]{2}{*}{$3 * *$} & .266 & .031 & .031 & 1969 & 1 & 7 & 4 & 4 & 3 \\
\hline & & & & 1969 & 2 & 8 & 2 & 2 & 6 \\
\hline $4 * *$ & .266 & .031 & .031 & 1970 & 2 & 7 & 4 & 4 & 3 \\
\hline 5 & .133 & .016 & .079 & 1975 & 1 & 7 & 2 & 4 & 3 \\
\hline 6 & .129 & .016 & - & 1973 & rep. & 7 & 0 & 1 & 6 \\
\hline $7 * *$ & .094 & .125 & - & 1966 & rep. & 8 & 0 & 2 & 6 \\
\hline $8^{* *}$ & .094 & .125 & - & 1967 & 1 & $9^{-6}$ & 0 & 0 & 3 \\
\hline $9 * *$ & .094 & .125 & - & 1966 & 1 & 9 & 0 & 0 & 8 \\
\hline \multirow[t]{2}{*}{10} & .094 & .016 & - & 1968 & 1 & $10^{-8}$ & 0 & 0 & 2 \\
\hline & & & & 1968 & 2 & 9 & 0 & 2 & $1^{*}$ \\
\hline 11 & .083 & .078 & - & 1972 & 1 & 8 & 0 & 0 & 8 \\
\hline $12 * *$ & .086 & .093 & .016 & 1970 & 1 & 10 & 0 & 4 & $0^{*}$ \\
\hline \multirow[t]{2}{*}{$13 * *$} & .075 & .016 & .016 & 1971 & 1 & 11 & 1 & 3 & 8 \\
\hline & & & & & 2 & 9 & 1 & 2 & $0^{*}$ \\
\hline 14 & .075 & .016 & .063 & 1977 & 1 & 8 & 3 & 3 & 5 \\
\hline \multirow[t]{4}{*}{15} & .031 & .016 & - & 1967 & 1 & $10^{-7}$ & 0 & 1 & 2 \\
\hline & & & & 1967 & 2 & $10^{-3}$ & & & $3 *$ \\
\hline & & & & 1968 & 1 & $11^{-9}$ & 1 & 1 & 1 \\
\hline & & & & 1968 & 2 & 7 & 0 & 0 & $4^{*}$ \\
\hline 16 & .031 & .016 & - & 1977 & 1 & 10 & 0 & 1 & 6 \\
\hline \multirow[t]{2}{*}{$17 * *$} & .043 & .016 & .047 & 1969 & 1 & 10 & 0 & 0 & 6 \\
\hline & & & & 1969 & 2 & 8 & 0 & 0 & 8 \\
\hline $18 * *$ & .028 & .083 & - & 1973 & 1 & 10 & 2 & 2 & 3 \\
\hline $19 * *$ & .016 & .008 & - & 1977 & 1 & 9 & 1 & 3 & 6 \\
\hline $20 * *$ & .016 & .008 & - & 1977 & 1 & 9 & 0 & 2 & 7 \\
\hline \multirow[t]{2}{*}{21} & .016 & .094 & - & 1968 & 1 & $8^{-4}$ & 0 & 0 & 2 \\
\hline & & & & & 2 & 6 & 0 & 0 & $1^{*}$ \\
\hline \multirow[t]{2}{*}{22} & .016 & .063 & - & 1973 & 1 & 9 & 3 & 3 & 6 \\
\hline & & & & 1974 & 1 & 7 & 3 & 3 & 4 \\
\hline 23 & .016 & .031 & - & 1967 & rep. & $9^{-5}$ & 0 & 0 & $0^{*}$ \\
\hline 24 & .008 & .016 & - & 1975 & 1 & 9 & 0 & 0 & 7 \\
\hline
\end{tabular}

* Pair 10, 6 nestlings were removed from second clutch in 1968. Pair 12, 6 nestlings were removed from first clutch in 1970. Pair 13, 6 nestlings were removed from second clutch in 1971. Pair 15, 4 nestlings were removed from second clutch in 1967, 3 nestlings were removed from second clutch in 1968. Pair 21, 3 nestlings were removed from second clutch in 1968. Pair 23, 4 nestlings were removed from repeat clutch in 1967.

** Pair 3 and pair 4 have the same male, the females are cousins. Pair 7 and pair 8 have the same female, the males are brothers. Pair 9 , the female is a sister of the female in pair 7 and 8 . Pair 12 and pair 13 have the same male. Pair 17 and pair 10 have the same female. Pair 18 , the female is a daughter of pair 11. Pair 19 and pair 20, the two females are sisters and the two males are brothers. 